\title{
ATRIBUTOS FÍSICOS E QUÍMICOS DE SUBSTRATOS COMPOSTOS POR BIOSSÓLIDOS E CASCA DE ARROZ CARBONIZADA ${ }^{(1)}$
}

\author{
I. A. GUERRINI (2) \& R. M. TRIGUEIRO(3)
}

\begin{abstract}
RESUMO
O objetivo deste trabalho foi estudar os atributos físicos e químicos de substratos com diferentes doses de biossólido (BIO) e de casca de arroz carbonizada (CAC), com vistas em obter um meio de cresci mento adequado para o desenvolvimento de mudas. Desta forma, utilizando biossólido proveniente da SABE SP, estação de Franca (SP), estabeleceu-se um ensaio com os seguintes tratamentos (propor ções BIO/CAC): 100/0, 90/10, 80/20, 70/30, 60/40, 50/50, 40/60, $30 / 70,20 / 80,10 / 90$ e 0/100, os quais foram comparados ao substrato comercial Multi plant ${ }^{\circledR}$. Foram realizadas análises para determinação dos atri butos físicos, como: densidade aparente do substrato, macro e microporosidade, porosidade total, capacidade máxima de retenção de água, e dos atributos químicos dos substratos, como: teores totais de macro e micronutrientes, $\mathrm{pH}$, relação $\mathrm{C} / \mathrm{N}$ e condutividade elétrica. Com a elevação da dose de BIO no substrato houve aumento da densidade e do percentual de microporos e, conseqüentemente, da capacidade de retenção de água. O BIO apresentou teores razoáveis de nutrientes com destaque para $\mathbf{N}$ e $P$, mas baixos teores de $K$. Não foram detectados teores de metais pesados superiores aos li mites estabelecidos pela Legislação Brasileira no biossólido usado. Comparando-se os valores considerados adequados para o desenvolvimento de mudas encontrados na literatura com os obtidos neste trabalho, encaixaram-se na faixa adequada os substratos cujas doses de biossólido variaram de 30 a $60 \%$. Nenhum substrato testado, incluindo o do tratamento com substrato comercial, apresentou valores ideais em todas as propriedades estudadas.
\end{abstract}

Termos de indexação: resíduos sólidos urbanos, substratos, aeração, retenção de água, biossólido.

(1) Parte da Tese de Mestrado do segundo autor, apresentada à Faculdade de Ciências Agronômicas - UNESP-Botucatu. Rcebido para publicação em janeiro de 2002 e aprovado em outubro de 2004.

(2) Professor Adjunto do Departamento de Recursos Naturais/Ciência do Solo da Faculdade de Ciências Agronômicas - UNESP. CEP 18603-970 Botucatu (SP). Bolsista do CNPq. E-mail: iguerrini @fca.unesp.br

(3) Doutorando em Agronomia, Área de concentração: Energia na Agricultura, UNESP. E-mail: trigueiro@fca.unesp.br. 


\title{
SUMMARY: PHYSICAL AND CHEMICAL ATTRIBUTES OF SUBSTRATES COMPOSED OF BIOSOLIDS AND CARBONIZED RICE CHAFF
}

\begin{abstract}
The objective of this research was to study the physical and chemical properties of substrates with different mixtures of biosolids (BIO) and carbonized rice chaff (CAC) in order to get an appropriate medium for seedling development. The experiment was established in thenursery of theDepartment of Natural Resources/ Forest Sciences, College of Agronomic Sciences, State University of São Paulo-FCA/ UNESP-Botucatu (SP), using $\mathrm{BIO}$ from SABESP/ Franca-SP and CAC in the following ratios (BIO/ CAC): 100/ 0, 90/ 10, 80/ 20, 70/30,60/ 40,50/50,40/60,30/70, 20/80, 10/90, and 0/ 100, which were compared to Multiplant ${ }^{\circledR}$ substrate. Theevaluated physical attributes were apparent density, macro and mi croporosity, total porosity, maximum water hol ding capacity. The fol lowing chemical attributes wereal so determi ned: macro and mi cronutrients concentration, pH, C/ $\mathrm{N}$ ratio, and electrical conductivity. Results showed an increasein density and microporosity with increasing $\mathrm{BIO}$ rates in thesubstrateand, consequently, an increasein thewater hol ding capacity. Chemical analyses showed high nutrient contents in BI O, especially $\mathrm{N}$ and $\mathrm{P}$, but a low $\mathrm{K}$ content. Leavy metal contents were below the limits defined by the Brazilian legislation. According to literature values considered adequate for plant growth, the satisfactory $\mathrm{BIO}$ rates in the substrateranged from 30 to $60 \%$. No substrate, including a control with a commercial substrate, presented ideal values for all evaluated parameters.
\end{abstract}

Index terms: municipal solid waste, substrate, nutrient, aeration, water retention.

\section{INTRODUÇÃO}

O biossólido, nome comercial do lodo de esgoto após sofrer um processo de estabilização, constitui a parte sólida do esgoto (cerca de 0,01\%). É um resíduo que pode ser utilizado como condicionador das propriedades físicas, químicas e biológicas do solo, considerando seu teor de matéria orgânica e nutrientes (Melo et al., 1994; Vanzo et al., 2001). Uma das aplicações deste material compreende o fornecimento de matéria orgânica na composição de substratos para a formação de mudas frutíferas e florestais, dentre outras.

Os substratos para a produção de mudas podem ser definidos como sendo o meio adequado para sua sustentação e retenção de quantidades suficientes e necessárias de água, oxigênio e nutrientes, além de oferecer pH compatível, ausência de elementos químicos em níveis tóxicos e condutividade el étrica adequada. A fase sólida do substrato deve ser constituída por uma mistura de partículas minerais e orgânicas. O estudo do arranjo percentual desses componentes é importante, já que eles poderão ser fonte de nutrientes e atuarão diretamente sobre o crescimento edesenvolvimento das plantas. Portanto, em decorrência do arranjo quantitativo e qualitativo dos materiais minerais e orgânicos empregados, as mudas serão influenciadas pelo suprimento de nutrientes, água disponível e oxigênio (Rosa J r. et al., 1998).

A matéria orgânica éum componentefundamental dos substratos, cuja final idade básica, de acordo com Cordell \& Filer J r. (1984), é aumentar a capacidade de retenção de água e nutrientes para as mudas.
Devem-se, ainda, considerar outras vantagens desse componente sobre o desenvolvimento vegetal, tais como: redução na densidade aparente e global e aumento da porosi dade do meio, características que podem ter uma partici pação positiva dos materiais orgânicos.

Gonçalves \& Poggiani (1996) agruparam os diversos substratos para produção de mudas florestais, levando em conta suas características químicas e físicas semel hantes, bem como seus potenciais similares para propagação de plantas. A partir das informações reveladas em vários trabal hos de pesquisa, pôde-se inferir que a mistura de substratos de um mesmo grupo não resulta em grandes alterações das características do produto obtido. Nesta linha de raciocínio, justifica-se o uso de, no máximo, três componentes em uma mistura de substratos para propagação de mudas florestais (Gonçalves et al., 2000). Os mesmos autores relataram que substratos adequados para a propagação de mudas via semente e estaca podem ser obtidos a partir da mistura de 70 a $80 \%$ de um componente orgânico (esterco de bovino, casca de eucalipto ou pinus, bagaço de cana, lixo urbano, outros resíduos e húmus de mi nhoca), com 20 a $30 \%$ de um componente usado para elevar a macropor osidade (casca de arroz carbonizada, cinza de caldeira de biomassa, bagaço de cana carbonizado).

A formação de mudas florestais de boa qualidade envolve os processos de germinação de sementes, iniciação radicular eformação do sistema radicular e parteaérea, que estão diretamenterelacionados com características que definem o nível de eficiência dos substratos, tais como: aeração, drenagem, retenção 
deágua e disponibilidade balanceada denutrientes. Por sua vez, as características dos substratos são altamentecorrelacionadas entresi: a macroporosidade com aeração e drenagem, e a microporosidade com a retenção de água e nutrientes (Gonçalves \& Poggiani, 1996; Caldeira et al., 2000).

Estudando a influência do uso de acículas de pinus e biossólidos em substrato na formação de ectomicorrizas em mudas de pinus, Bettiol et al. (1986) verificaram que as doses de biossólidos utilizadas (de0 à 10 \%, v/v) não influíram na formação de ectomicorrizas, nem no desenvolvimento das mudas de Pinus caribaea var. hondurensis inoculadas com o fungo Thel ephora terrestris. Entretanto, a formação de ectomi corrizas pel o fungo Pisolithus tinctorius foi inibida pelas fontes de matéria orgânica em todas as doses utilizadas, tendo sido o biossólido maior inibidor do que as acículas.

Morais et al. (1997), comparando esterco bovino, biossólido e acículas de pinus, comprovaram que o melhor crescimento em diâmetro do colo e altura total para mudas de Cedro (Cedrela fissilis Vell) na fase de viveiro foi obtido em mudas que continham a mistura 70 \% solo sem adubação +30 \% biossólido, seguido pel o tratamento $70 \%$ solo sem adubação + $30 \%$ esterco bovino. E em relação à produção de matéria seca, esses mesmos tratamentos promoveram os maiores ganhos, concluindo que o uso do biossólido durante a fase de viveiro é uma alternativa viável como substrato orgânico em mudas de cedro.

O objetivo deste estudo foi avaliar os atributos físicos equími cos de substratos com diferentes doses de biossólido (BIO) e de casca de arroz carbonizada (CAC), visando determinar a mel hor proporção entre esses componentes para a formação de um meio de crescimento adequado para o desenvolvimento de mudas de espécies florestais.

\section{MATERIAL E MÉTODOS}

O experimento foi realizado no período de junho a dezembro de 2001, nas instalações da Fazenda
Experimental Lageado, pertencenteà Faculdade de Ciências Agronômicas (FCA) da UNESP, no município de Botucatu, São Paulo.

O biossólido utilizado no experimento foi doado pela Companhia de Saneamento Básico do estado de São Paulo (SABESP), produzido pela Estação de Tratamento de Esgotos da cidade de Franca (SP). O resíduo produzi do nessa estação é classificado pelo Ministério da Agricultura como condicionador de solo. Este material é produto da digestão anaeróbia do lodo de esgoto residencial e industrial da cidade deFranca. No processo de desidratação, é utilizado um polieletrólito catiônico adicionado à massa do biossóli ido em torno de 3,2 a 4,3 \% (kg de poliel etrólito por $100 \mathrm{~kg}$ de biossólido seco), resultando em um material com teor de sólidos variando de 17,2 a 19,5 \% (Vanzo et al., 2001).

Os biossólidos produzidos na ETE de F ranca são classificados como de "excepcional qualidade" para - uso agrícola, segundo a norma norte-americana EPA 40 CFR Part 503 (USPA, 1993), graças ao fato de ser a concentração de metais pesados nos biossólidos extremamente baixa (Quadro 1). Este material foi ainda classificado como biossól ido Classe B pela mesma norma norte-americana (EPA 40 CFR Part 503; USEPA, 1993) e pela norma P 4.230 da Companhia de Tecnologia deSaneamento Ambiental (CETESB, 1999), visto quea concentração média de coliformes fecais é de $486.000 \mathrm{NMP} / \mathrm{gST}$ (número mais provável por grama de sólidos totais), inferior ao limite máximo para biossólido Classe $B$, queé de 2.000.000 NMP/gST (Vanzo et al., 2001).

O produto foi expedido com alta umidade, cerca de $80 \%$, sendo necessário realizar sua secagem, que foi feita ao ar, no interior de casa de vegetação, espal hando-se o material sobre lona plástica. Após a secagem completa, o material foi triturado em picador-moedor de forragem adaptado, de forma a reduzir o tamanho dos grânul os à peneira de $4 \mathrm{~mm}$.

A casca de arroz carbonizada foi fornecida pela Fazenda Experimental Lageado-FCA/UNESP, onde foram realizados os processos de beneficiamento do arroz e carbonização de sua casca.

\section{Quadro 1. Concentração de metais pesados em biossólidos da ETE de Franca}

\begin{tabular}{lccc}
\hline $\begin{array}{c}\text { Metal pesado } \\
\text { poluente }\end{array}$ & $\begin{array}{c}\text { Concentração } \\
\text { base seca(1) }\end{array}$ & $\begin{array}{c}\text { Biossólido de excepcional } \\
\text { qualidade (EPA 40 CFR Part 503) }\end{array}$ & $\begin{array}{c}\text { Limite máximo para uso } \\
\text { agrícola (E PA 40 CFR Part 503) }\end{array}$ \\
\hline & & & $\mathrm{mg} \mathrm{kg}^{-1}$ \\
Arsênio & $\mathrm{ND}$ & 41 & 75 \\
Cádmio & 0,25 & 39 & 85 \\
Cobre & 241500 & 4300 \\
Chumbo & 0,59 & 300 & 540 \\
Mercúrio & $N D$ & 17 & 75 \\
Molibdênio & $N D$ & $N D$ & 420 \\
Níquel & 3,90 & 420 & 100 \\
Selênio & $N D$ & 100 & 7500 \\
Zinco & 911 & 2800 & \\
\hline
\end{tabular}

\footnotetext{
(1) Resultados obtidos neste trabalho. ND - Não detectado.
} 
Foram estipuladas as misturas nas proporções de 0 a 100 \% de bi ossóli do (BI O) em composi ção com casca de arroz carbonizada (CAC). Cada mistura (\% BIO / \% CAC) compôs um tratamento: T 01-100/ 0; T 02-90/10; T 03-80/20; T 04-70/30; T 05-60/40; T 06-50/50; Т 07-40/60; Т 08-30/70; T 09-20/80; T 10-10/90; T 11-0/100. Estes foram comparados à testemunha ( $\mathrm{T} \mathrm{12}$ ), que consistiu do substrato comercial Multiplant ${ }^{\circledR}$ (60\% de composto de casca de pinus, $15 \%$ de vermiculita e $25 \%$ de húmus e terra vegetal) utilizado pelo referido viveiro.

O experimento consistiu de um delineamento inteiramente casualizado com 12 tratamentos e quatro repetições; aplicou-se o teste $\mathrm{F}$ para análise de variância dos atributos químicos e o teste de Tukey para a comparação das médias no caso de significância. Para avaliar os atributos físicos, foi realizada análise de regressão, utilizando o programa Sigma Stat 2.0 (J andel Scientific).

De acordo com as proporções estipuladas para cada tratamento, foram realizadas as misturas dos componentes casca de arroz carbonizada e biossólido e, após a homogeneização dos materiais, os substratos foram acondicionados em sacos plásticos, dos quais foram retiradas quatro amostras (repetições) por tratamento. O mesmo procedimento foi adotado para a amostragem do substrato comercial. As amostras foram colocadas em sacos plásticos de 1,0 L devidamente identificados e, de cada amostra, foram retiradas as quantidades necessárias para as análises.

A análise química dos substratos baseou-se no método de fertilizantes orgânicos, a qual determina os teores de nutrientes totais contidos nos materiais analisados. Essas análises foram efetuadas pelo Laboratório deAnálise de F ertilizantes eCor retivos do Departamento de Recursos Naturais/Ciência do Solo, conformeorientação doMinistério da Agricultura (Brasil, 1988). As análises para detecção de metais pesados no biossól ido foram real izadas por E spectrometria de E missão Atômica com Plasma de Argônio, determinadas em extrato nítrico-perclórico, de acordo com o método descrito por Malavolta et al. (1997).

Para caracterização física do substrato comercial e dos substratos dos tratamentos, foram realizadas análises de densidade, porosidade total, macroporosidade, microporosidade e capacidade máxima de retenção de água.

Foram utilizados tubetes de polipropileno com capacidade volumétrica de $50 \mathrm{~cm}^{3}$, os quais tiveram a abertura inferior fechada com um botão de quatro furos para evitar a perda de material durante a determinação dos atributos físicos do substrato. Os recipientes foram identificados, pesados e preenchidos manual mente com substrato, o qual foi compactado, usando-se um equi pamento que simula as batidas para o adensamento das partículas, semelhante ao que é utilizado para a produção de mudas em escala comercial.
Após o preenchimento dos tubetes, o substrato foi submetido à saturação por água. O período inicial deencharcamentofoi de $1 \mathrm{~h}$; em seguida, os tubetes foram colocados para drenagem por $30 \mathrm{~min}$. A primeira pesagem foi efetuada com o substrato encharcado. Para a segunda pesagem foi feita a drenagem, que foi realizada em duas etapas, sendo a primeira com o tubete suspenso, com a superfície de drenagem livre durante $1 \mathrm{~h}$. Depois, os tubetes foram mantidos em drenagem com o fundo em contato com fol has de papel jornal e uma lâmina de espuma plástica por mais $12 \mathrm{~h}$. Em seguida, transferiu-se o substrato drenado para cápsulas de Al com tampa, as quais foram levadas para estufa regulada a $105^{\circ} \mathrm{C}$, onde permaneceram por $24 \mathrm{~h}$. Após este período, as cápsulas foram retiradas da estufa, tampadas imediatamente etransferidas para o dessecador, sendo pesadas após o resfriamento. Maiores detalhes desse método podem ser encontrados em Silva (1998).

Para determinar os atributos físicos, foram usadas as seguintes fórmulas:

$$
\begin{aligned}
& \text { Macroporosidade }(\%)=[(A-B) / C] \times 100 \\
& \text { Microporosidade }(\%)=[(B-D-E) / C] \times 100 \\
& \text { Porosidade total }(\%)=\text { Macroporosidade + } \\
& \text { Microporosidade }
\end{aligned}
$$

Capacidade máxima de retenção de água $(\mathrm{mL}$ $50 \mathrm{~cm}^{-3}$ ) $=\mathrm{B}-\mathrm{D}-\mathrm{E}$

Densidade aparente do substrato $=(D-E) / C$ em que $A$ = peso do substrato encharcado; $B=$ peso do substrato drenado; $C=$ volume do conteiner(4); $D$ = peso do substrato seco; $\mathrm{E}=$ peso do conteiner.

Para determinar a condutividade elétrica dos substratos, foram colocados $50 \mathrm{~mL}$ da amostra de substrato mais $250 \mathrm{~mL}$ deágua dei onizada em frasco de $300 \mathrm{~mL}$, agitando-se por $30 \mathrm{~min}$. Após $30 \mathrm{~min}$ de repouso, as amostras foram filtradas e as determinações feitas no extrato aquoso com auxílio do condutivímetro DIGIMED modelo DM 3 Digimed I nstrumentação Analítica.

\section{RESULTADOS E DISCUSSÃO}

\section{Atributos físicos}

Observou-se que, à medida que se el evou a dose de biossólido no substrato, ocorreu um aumento da sua densidade e, conseqüentemente, redução da macroporosidade (Figura 1), como observado também por Stringheta et al. (1997), em estudos usando como substrato composto de lixo urbano em mistura com casca de arroz carbonizada.

\footnotetext{
(4) Tubetes de polipropileno com capacidade de $50 \mathrm{~cm}^{3}$.
} 
biossólido, tratado com polieletrólitos, apresentou alta capacidade de perder água e demanter-senesta condição. Este material, quando seco, tornou-se bastante coeso, necessitando-se realizar moagem a fim de reduzir o tamanho dos grânulos com que se desejava trabalhar. Esta característica dobiossólido conferiu ao substrato uma textura granular grosseira, que poderia levar erroneamente à conclusão de ser este material capaz de conferir ao substrato maior aeração. Esta condiçãofoi alterada com o umedecimento do substrato, o qual se expandiu ao absorver água, aumentou seu volume e, assim, ocupou espaços livres dentro do reci piente.

Por ser a casca de arroz carbonizada um material leve e inerte à hidratação, obteve-se um acréscimo na porosidade do substrato à medida que se el evou a percentagem deste componente na mistura, principalmente pela elevação no percentual de macroporos. Esta informação corrobora os resultados obtidos por Gonçalves \& Poggiani (1996), os quais observaram que, normal mente, substratos mais leves, de baixa densidade, como materiais incinerados e vermiculita, el evavam a macroporosidade das misturas e reduziam a capacidade de retenção de água do substrato. De forma contrária, quando se aumentou a quantidade de biossólido nas misturas, obteve-se diminuição na porosidade total, mesmo com a elevação proporcionada em microporosidade(Figura 1). Esta característica de materiais com altos valores de matéria orgânica, como o biossólido, também foi observada por Moraes Neto et al. (2001), trabal hando com substratos à base de húmus de minhoca e casca de arroz carbonizada, e por Stringheta et al. (1997).
O aumento na dose de biossólido nas misturas elevou a microporosidade do substrato, o que proporcionou maior capacidade em reter água (Figura 1). Aumentos na dose de casca de arroz carbonizada promoveram redução na proporção de microporos do substrato, reduzindo sua capacidade de retenção de água, tornando inviável, para a produção de mudas, o uso de altas doses desse componente, em virtude do alto consumo de água para irrigação. A capacidade de retenção de água foi tanto maior quanto maior foi a dose de biossólido no substrato; porém, em substratos com altas doses de biossólidos, observou-sealta densidade (Figura 1) e, conseqüentemente, redução da proporção de macroporos, fato este que dificulta a aeração dos substratos, prejudicando o desenvolvimento do sistema radicular. Para De Boodt \& Verdonck (1972), citados por Kämpf \& Fermino (2000) e Gonçal ves \& Poggiani (1996), o substrato ideal deve ter de 75 a $85 \%$ de seu volume em poros.

A quantidadeea qualidadede poros determinaram a distribuição de sólidos, água e ar nos substratos (Figura 2).

O substrato Multiplant ${ }^{\circledR}$ (Figura 2) apresentou percentagem de microporos considerada adequada (45-55 \%), segundo padrão definido por Gonçalves \& Poggiani (1996), conferindo a este substrato uma capacidade de retenção de água satisfatória. A macroporosidade e a densidade desse material apresentaram val ores consi derados médi os por esses autores (respectivamente, $20-40 \%$ e 0,25-0,50 $\mathrm{g} \mathrm{cm}^{-3}$ ). Esse conjunto de características conferiu ao substrato qualidade para o desenvolvimento do sistema radicular das mudas.
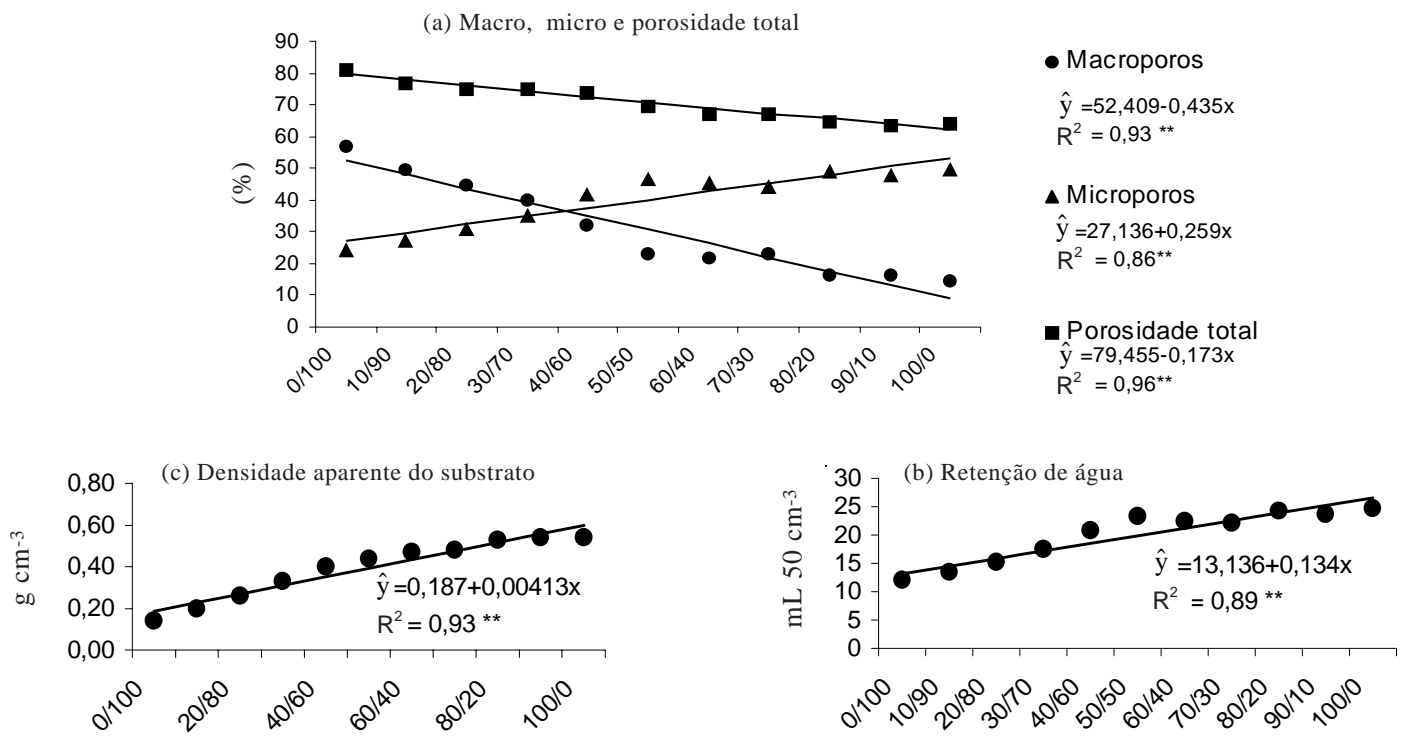

BIOSSÓDO/CASCA DE ARROZ CARBONIZADA

Figura 1. Macroporos (a), microporos, porosidade total (b) e capacidade máxima de retenção de água e (c) densidade aparente dos substratos. 
Os valores atribuídos às características físicas (Figura 1), comparados com valores obtidos para o substrato-testemunha e, segundo informações de Kämpf \& Fermino (2000) e Gonçalves \& Poggiani (1996), permitiram considerar mais adequados para o desenvol vimento de mudas florestais os substratos cujas quantidades de biossólido variaram de 30 a $60 \%$.

\section{Atributos químicos}

O biossólido contém teores razoáveis de nutrientes, com destaque para N e P (Quadro 2). A casca de arroz carbonizada, por sua vez, é um material pobreem nutrientes, apresentando apenas o teor de $\mathrm{K}\left(\mathrm{K}_{2} \mathrm{O}\right)$ mais el evado. A alteração na proporção da mistura refletiu-se significativamente

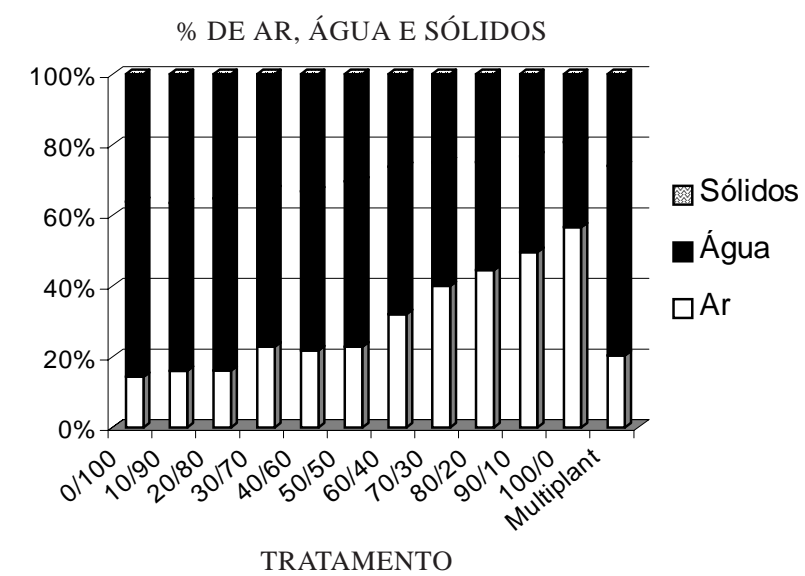

Figura 2. Distribuição de sólidos, água e ar nos diversos substratos analisados. na composi ção química dos substratos. Dessa forma, à medida que se reduziu a quantidade de biossólido no substrato, houve redução nos teores dos nutrientes $\mathrm{N}, \mathrm{P}_{2} \mathrm{O}_{5}, \mathrm{Ca}$, Mge S edematéria orgânica. Por outro lado, o teor de $\mathrm{K}_{2} \mathrm{O}$ elevou-se graças ao aumento na dose de casca de arroz carbonizada, que contém maior quantidade desse nutriente que o biossólido. O substrato-testemunha apresentou, em geral, baixos teores de nutrientes, característica comum em substratos comerciais.

$\mathrm{Na}$ análise de micronutrientes (Quadro 3), o biossól ido apresentou teores mais el evados para Zn, $\mathrm{Cu}$ e $\mathrm{Fe}$, enquanto a casca de arroz carbonizada apresentou maior teor de Mn. Portanto, assim como para macronutrientes, à medida que se reduziu a dosagem de biossólido no substrato, obteve-se redução nos teores de $\mathrm{Zn}, \mathrm{Cu}$ e $\mathrm{Fe}$, bem como aumento no teor de $\mathrm{Mn}$. O substrato-testemunha apresentou baixos teores de mi cronutrientes, quando comparados ao dos tratamentos com biossólido.

Todos os tratamentos apresentaram valores de $\mathrm{pH}\left(\mathrm{CaCl}_{2}\right)$ (Quadro 3) dentro da faixa considerada adequada para o desenvolvimento demudas, ou seja, de 5,5 a 6,5, segundo Gonçalves \& Poggiani (1996) e Valeri \& Corradini (2000).

A condutividade elétrica aumentou à medida que aumentou a dose de biossólido na mistura, em razão da carga de sais deste material. Segundo Gonçalves et al. (2000), a condutividade elétrica do substrato não deve ficar acima de $1,0 \mathrm{mS} \mathrm{cm}^{-1}$, em determinações realizadas a partir de extrato de diluição de 1:1,5. Portanto, observou-se que, com exceção dos tratamentos 20/80, 10/90 e 0/100, os demais apresentaram condutividade el étrica acima

Quadro 2. Teores totais de macronutrientes, carbono e matéria orgânica dos substratos nos diversos tratamentos

\begin{tabular}{|c|c|c|c|c|c|c|c|c|}
\hline $\begin{array}{l}\text { Tratamento(1) } \\
\text { (BIO/CAC) }\end{array}$ & $\mathbf{N}$ & $\mathbf{P}_{2} \mathbf{O}_{5}$ & $\mathrm{~K}_{2} \mathrm{O}$ & MO & C & $\mathrm{Ca}$ & Mg & $\mathbf{S}$ \\
\hline & \multicolumn{8}{|c|}{$\%(p / p)$} \\
\hline $100 / 0^{(1)}$ & $5,72 \mathrm{a}$ & $2,53 \mathrm{~b}$ & $0,11 \mathrm{f}$ & $60,00 a b$ & $33,40 \mathrm{bcd}$ & $1,67 \mathrm{a}$ & $0,22 \mathrm{a}$ & $1,01 a b c d$ \\
\hline $90 / 10$ & $5,17 \mathrm{ab}$ & 3,05 a & $0,11 \mathrm{f}$ & $60,00 a b$ & 33,42 bc & $1,54 a b$ & $0,21 a b$ & $1,25 a b$ \\
\hline $80 / 20$ & $5,14 a b c$ & 2,48 bc & 0,13 ef & 61,00 a & $33,90 a b$ & $1,41 \mathrm{abc}$ & $0,21 a b$ & $1,39 a$ \\
\hline $70 / 30$ & 4,87 bc & $2,26 \mathrm{bcd}$ & 0,15 def & $59,50 a b$ & $32,95 \mathrm{bcd}$ & $1,37 \mathrm{bcd}$ & $0,20 a b$ & $0,88 \mathrm{abcd}$ \\
\hline $60 / 40$ & 4,92 bc & 2,09 cde & 0,23 cde & $60,00 a b$ & $33,40 \mathrm{bcd}$ & 1,30 bcde & 0,16 abcd & $1,09 a b c$ \\
\hline $50 / 50$ & $4,75 \mathrm{bc}$ & $1,99 \mathrm{de}$ & 0,22 cde & $59,50 a b$ & $33,10 \mathrm{bcd}$ & 1,11 def & $0,18 a b c$ & $1,37 \mathrm{a}$ \\
\hline $40 / 60$ & $4,51 \mathrm{C}$ & 1,76 ef & $0,23 \mathrm{~cd}$ & $58,75 a b$ & $32,67 \mathrm{bcd}$ & 1,23 cde & 0,16 abcd & $0,67 \mathrm{bcde}$ \\
\hline $30 / 70$ & 3,52 de & 1,72 ef & $0,30 \mathrm{bc}$ & $57,75 \mathrm{~b}$ & $32,20 \mathrm{~cd}$ & 1,07 efg & 0,16 abcd & 0,64 bcde \\
\hline $20 / 80$ & $3,68 \mathrm{~d}$ & $1,43 \mathrm{fg}$ & $0,38 \mathrm{~b}$ & $57,75 \mathrm{~b}$ & $32,22 \mathrm{~cd}$ & $0,92 \mathrm{fgh}$ & $0,14 \mathrm{bcd}$ & 0,60 cdef \\
\hline $10 / 90$ & $2,97 \mathrm{e}$ & $1,10 \mathrm{~g}$ & $0,40 \mathrm{~b}$ & $57,75 \mathrm{~b}$ & $31,95 \mathrm{~d}$ & $0,74 \mathrm{~h}$ & $0,12 \mathrm{~cd}$ & 0,43 def \\
\hline $0 / 100$ & $0,56 \mathrm{f}$ & $0,16 \mathrm{~h}$ & $0,63 \mathrm{a}$ & $58,25 \mathrm{~b}$ & $35,14 \mathrm{a}$ & $0,21 \mathrm{i}$ & $0,10 \mathrm{~d}$ & $0,02 \mathrm{f}$ \\
\hline Multiplant $^{\circledR}$ & $0,63 \mathrm{f}$ & $0,41 \mathrm{~h}$ & 0,15 def & $28,50 \mathrm{c}$ & $15,85 \mathrm{e}$ & $0,82 \mathrm{gh}$ & $0,15 \mathrm{abcd}$ & 0,15 ef \\
\hline D.M.S. & 0,64 & 0,41 & 0,10 & 2,281 & 1,45 & 0,27 & 0,07 & 0,62 \\
\hline C.V. (\%) & 6,69 & 9,40 & 16,05 & 1,63 & 1,40 & 9,68 & 17,77 & 31,72 \\
\hline
\end{tabular}

(1) BIO/CAC = Biossólido/Casca de arroz carbonizada. **significativo a 1 \%. Médias seguidas de mesma letra, na coluna, não diferem estatisticamente entre si pelo teste Tukey $(P>0,05)$. 
Quadro 3. Teores totais de micronutrientes e valores de $\mathrm{pH}$, relação $\mathrm{C} / \mathrm{N}$ e condutividade elétrica dos substratos nos diversos tratamentos

\begin{tabular}{|c|c|c|c|c|c|c|c|c|}
\hline $\begin{array}{c}\text { Tratamento(1) } \\
\text { (BIO/CAC) }\end{array}$ & $\mathrm{Na}$ & Zn & $\mathrm{Cu}$ & Mn & $\mathbf{F e}$ & pH $\mathrm{CaCl}_{2}$ & $\mathrm{C} / \mathrm{N}$ & CE Ext. 1:5 \\
\hline & \multicolumn{5}{|c|}{$-\mathrm{mg} \mathrm{kg}^{-1}$} & & & $\mathrm{mS} \mathrm{cm}-1$ \\
\hline $100 / 0^{((1)}$ & 0,117 & 911,63 a & $240,90 \mathrm{a}$ & $160,88 \mathrm{e}$ & 20515 a & $6,40 \mathrm{~b}$ & $7 / 1 \mathrm{~d}$ & $2,99 \mathrm{a}$ \\
\hline $90 / 10$ & 0,110 & $841,50 a b$ & $210,38 a b$ & $160,05 \mathrm{e}$ & $20171 a b$ & $6,30 \mathrm{~b}$ & $7 / 1 \mathrm{~d}$ & $2,90 \mathrm{a}$ \\
\hline $80 / 20$ & 0,113 & $810,98 a b c$ & 202,13 b & $171,60 \mathrm{e}$ & 18040 abc & $6,30 \mathrm{~b}$ & $7 / 1 \mathrm{~d}$ & $3,02 \mathrm{a}$ \\
\hline $70 / 30$ & 0,103 & $789,53 \mathrm{bc}$ & 190,58 bc & $181,50 \mathrm{e}$ & 16335 abcd & $6,33 b$ & $7 / 1 \mathrm{~d}$ & $2,96 \mathrm{a}$ \\
\hline $60 / 40$ & 0,115 & $782,10 \mathrm{bc}$ & 189,75 bc & $187,28 \mathrm{e}$ & 14671 bcde & $6,38 b$ & $7 / 1 \mathrm{~d}$ & $2,73 a$ \\
\hline $50 / 50$ & 0,115 & $660,00 \mathrm{de}$ & 153,45 de & 197,18 e & $12348 \mathrm{de}$ & $6,38 \mathrm{~b}$ & $8 / 1 \mathrm{~d}$ & $2,48 a$ \\
\hline $40 / 60$ & 0,110 & $720,23 \mathrm{dc}$ & $169,95 \mathrm{~cd}$ & 219,45 de & 12664 cde & $6,28 b$ & $8 / 1 d$ & $1,68 \mathrm{~b}$ \\
\hline $30 / 70$ & 0,330 & 653,40 de & 146,85 de & $264,00 \mathrm{~cd}$ & 12954 cde & $6,33 \mathrm{~b}$ & $10 / 1 \mathrm{~cd}$ & $1,43 \mathrm{~b}$ \\
\hline $20 / 80$ & 0,098 & 580,80 ef & 122,10 ef & 299,48 bc & 12306 de & $6,38 b$ & $10 / 1 \mathrm{~cd}$ & $0,71 \mathrm{c}$ \\
\hline $10 / 90$ & 0,085 & $471,08 \mathrm{f}$ & $90,75 \mathrm{f}$ & 338,25 b & $9144 \mathrm{e}$ & $6,45 b$ & $12 / 1 \mathrm{c}$ & $0,51 \mathrm{c}$ \\
\hline 0/100 & 0,078 & $105,60 \mathrm{~g}$ & $11,55 \mathrm{~g}$ & 546,98 a & $440 \mathrm{f}$ & $6,73 a$ & $63 / 1 \mathrm{a}$ & $0,09 \mathrm{c}$ \\
\hline Multiplant $^{\circledR}$ & 0,095 & $154,28 \mathrm{~g}$ & $33,00 \mathrm{~g}$ & $169,95 \mathrm{e}$ & $3039 \mathrm{f}$ & $5,03 \mathrm{c}$ & $28 / 1 b$ & $1,54 \mathrm{~b}$ \\
\hline D.M.S. & 0,31 & 113,2 & 31,96 & 62,26 & 5588 & 0,21 & 3,60 & 0,70 \\
\hline C.V. (\%) & 104,13 & 7,35 & 8,82 & 10,45 & 17,80 & 1,33 & 10,08 & 12,38 \\
\hline
\end{tabular}

(1) BIO/CAC = Biossólido/Casca de arroz carbonizada

**: significativo a $1 \%$. ns: não-significativo.

Médias seguidas de mesma letra, na coluna, não diferem estatisticamente entre si pelo teste Tukey $(P>0,05)$.

do considerado ideal, indicando excesso de sais solúveis nestes substratos, ainda mais considerando quea análise de condutividade elétrica dos materiais foi realizada em extrato resultante da diluição de uma parte de substrato para cinco partes de água. Entretanto, esse fator não influiu na produção de mudas de Eucalyptus grandis e Pinus taeda, conforme observado, respectivamente, por Trigueiro \& Guerrini (2003a, b).

A adubação de mudas, em geral, tem sido realizada independentemente da qualidade nutricional dos substratos, procurando-se para este fim substratos com baixos teores de nutrientes como éo caso do Multiplant ${ }^{\circledR}$. A carga de nutrientes presentes em materiais como o biossólido, conforme observado neste trabalho, pode, porém, promover significativa economia de fertilizantes aos viveiristas. Para tanto, há necessidade de conhecer a disponibilização denutrientes por estes substratos, considerar a real necessidade nutricional da espécie com que se trabalhará, e, assim, dominar a técnica de produção de mudas com substratos à base de biossólido.

O uso de biossólido, como componente de substratos, é mais uma alternativa viável para a disposição final deste resíduo, embora haja necessidade de maiores estudos sobre a liberação de nutrientes para que seu uso seja otimizado

\section{CONCLUSÕES}

1. O aumento na percentagem de biossólido e a conseqüenter reduçãona decasca dearroz carbonizada promoveram aumento na densidade aparente dos substratos, diminuindo o espaço de aeração, além de aumentar a capacidade de retenção de água pelo aumento na microporosidade dos substratos.

2. Em geral, a quantidade de nutrientes no substrato foi aumentada com a el evação da percentagem de biossólido, exceto para K e Mn.

3. Deacordo com as características apresentadas, foram consi derados mais adequados para o desenvolvimento de mudas de espécies fl orestais os substratos com 30 a $60 \%$ de biossólido no seu volume total .

4. Nenhum substrato testado, inclusive a testemunha, apresentou val ores considerados ideais em todos os atributos estudados.

\section{LITERATURA CITADA}

BETTIOL, W.; AUER, C.G.; KRUNER, T.L. \& PREZOTTO, M.E.M. Influência de lodo de esgoto e de acículas de pinus na formação da ectomi corrizas em mudas de Pinus cari baea var. hondurensis pelos fungos Pisolithus tinctorius e Thelephora terrestris. IPEF, 34:41-6, 1986.

BRASIL. Ministério da Agricultura. Análise de corretivos, fertilizantes einoculantes. Métodos oficiais. Brasília, 1988. 110p.

CALDEIRA, M.V.W.; SCHUMACHER, M.V.; BARICHELLO, L.R.; VOGET, H.L.M. \& OLIVEIRA, L.S. Crescimento de mudas de Eucalyptus saligna Smith em função de diferentes doses de vermicomposto. Floresta, 28:19-30, 2000.

COMPANHIA DE TECNOLOGIA DE SANEAMENTO AMBIENTAL - CETESB. Manual Técnico P.4.230 - jan/ 99. Aplicação de biossólido de sistemas de tratamento biológico em áreas agrícolas - Critérios para projeto e operação. São Paulo, 1999. 33p. 
CORDELL, C.E. \& FILER J r., T.H. Integrated nursery pest management. In: SOUTHERN PINE NURSERY HANDBOOK: Atlanta, USDA. Forest Service, Southern Region, 1984. p.1-17.

GONÇALVES, J.L.M. \& POGGIANI, F. Substratos para produção de mudas florestais. In: CONGRESSO LATINO AMERICANO DE CIÊNCIA DO SOLO, 13., Águas de Lindóia, 1996. Resumos. Piracicaba, Sociedade Latino Americana de Ciência do Solo, 1996. CD-ROM.

GONÇALVES, J L.M.; SANTARELLI, E.G.; MORAES NETO, S.P. \& MANARA, M.P. Produção de mudas de espécies nativas: substrato, nutrição, sombreamento e fertilização. In: GONÇALVES, J .L.M. \& BENEDETTI, V., eds. Nutrição e fertilização florestal. Piracicaba, IPEF, 2000. p.309-350.

KÄMPF, A.N. \& FERMINO, M.H. Substratos para plantas. A base da produção vegetal em recipientes. Porto Alegre, Genesis, 2000. 312p.

MALAVOLTA, E.; VITTI, G.C. \& OLIVEIRA, S.A. Avaliação do estado nutricional das plantas. 2.ed. Piracicaba, Associação Brasileira para Pesquisa da Potassa e do Fosfato, 1997. 319p.

MELO, W.J .; MARQUES, M.O.; SANTIAGO, G.; CHELI, R.A. $\&$ LEITE, S.A.S. Efeito de doses crescentes de lodo de esgoto sobre frações da matéria orgânica e CTC de um Latossolo cultivado com cana-de-açúcar. R. Bras. Ci. Solo, 18:449-455, 1994.

MORAES NETO, S.P.; GONÇALVES, J .L.M. \& TAKAKI, M. Produção de mudas de seis espécies arbóreas, que ocorrem nos domínios da floresta atlântica, com diferentes substratos de cultivo e níveis de luminosidade. R. Árvore, 25:277-287, 2001.

MORAIS, S.M.J .; ATAIDE, P.R.V.; GARCIA, D.C.; KURTZ, F.C.; OLIVEIRA, O.S. \& WAZLAWICK, L.F. Uso do lodo de esgoto da Corsan - Santa Maria (RS), comparado com outros substratos orgânicos. Sanare, 6:44-49, 1997.
ROSA J r., E.J .; DANIEL, O.; VITORINO, A.C.T. \& SANTOS FILHO, V.C. Efeito de diferentes substratos sobre o desenvolvimento de mudas de Eucalyptus grandis $\mathrm{Hill}$, em tubetes. R. Ci. Agr., 1:18-22, 1998.

SILVA, M.R. Caracterização morfológica, fisiológica enutricional de mudas de Eucalyptus grandis Hill ex Maiden submetidas a diferentes níveis de estresse hídrico. Curitiba, Universidade Federal do Paraná, 1998. 105p. (Tese de Mestrado)

STRINGHETA, A.C.O.; RODRIGUES, L.A.; FONTTES, L.E.F. \& COSTA, C.A. Caracterização física de substratos contendo composto de lixo urbano e casca de arroz carbonizada como condicionadores. R. Bras. Ci. Solo, 21:155-159, 1997.

TRIGUEIRO, R.M. \& GUERRINI, I.A. Uso de biossólidos como substrato para produção de mudas de eucalipto. Sci. For., 64:150-162, 2003.

TRIGUEIRO, R.M. \& GUERRINI, I.A. Produção de mudas de pinus em substrato composto por biossól ido e casca de arroz carbonizada. R. Ener. Agric., 12:1-12, 2003.

U.S. ENVIRONMENTAL PROTECTION AGENCY-USEPA. A guide to the biosolids risk assessments for theEPA Part 503 Rule. EPA/832-B-93-005. Office of wastewater management. Washington D.C., 1993. 144p.

VALERI, S.V. \& CORRADINI, L. Fertilização em viveiro para produção de mudas de Eucalyptus e Pinus. In: GONÇALVES, J.L.M. \& BENEDETTI, V. Nutrição e fertilização florestal. Piracicaba, IPEF , 2000. p.168-90.

VANZO, J .E.; MACEDO, L.S. \& TSUTIYA, M.T. Registros da produção de biossólidos. O caso da ETE de Franca. In: TSUTIYA, M.T; COMPARINI, J.B.; ALEM SOBRINHO, P.; HESPANHOL, I.; CARVALHO, P.C.T.; MELFI, A.J .; MELO., W.J . \& MARQUES, M.O., eds. Biossólidos na agricultura. São Paulo, SABESP, 2001. p.227-242. 